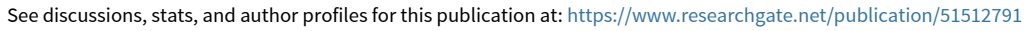

\title{
Electrospun Polyethylene Oxide (PEO) Nanofibers Containing Cyclodextrin Inclusion Complex
}

Article in Journal of Nanoscience and Nanotechnology · May 2011

Dol: 10.1166/jnn.2011.3867 . Source: PubMed

\section{CITATIONS}

31

3 authors:

Tamer Uyar

Bilkent University

240 PUBLICATIONS 4,299 CITATIONS

SEE PROFILE

Flemming Besenbacher

Aarhus University

806 PUBLICATIONS 40,304 CITATIONS

SEE PROFILE
311

Jale Hacaloglu

Middle East Technical University

130 PUBLICATIONS 1,601 CITATIONS

SEE PROFILE

Some of the authors of this publication are also working on these related projects:

Direct Investigation of Charge Transfer in Neurons by Electrostatic Force Microscopy View project

Manipulation and Characterization of the Lander molecules on the surface by an UHV-STM Investigation and Numerical Calculations. View project 


\title{
Electrospun Polyethylene Oxide (PEO) Nanofibers Containing Cyclodextrin Inclusion Complex
}

\author{
Tamer Uyar ${ }^{1,2, *}$, Jale Hacalogl $u^{4}$, and Flemming Besenbacher ${ }^{1,3}$ \\ 1 Interdisciplinary Nanoscience Center (iNANO), Aarhus University, DK 8000, Aarhus C, Denmark \\ ${ }^{2}$ UNAM-Institute of Materials Science \& Nanotechnology, Bilkent University, Ankara, 06800, Turkey \\ ${ }^{3}$ Department of Physics and Astronomy, Aarhus University, DK 8000, Aarhus C, Denmark \\ ${ }^{4}$ Department of Chemistry, Middle East Technical University, Ankara, 06531, Turkey
}

\begin{abstract}
In this study, we obtained functional electrospun nanofibers containing stable fragrance/flavor molecule facilitated by cyclodextrin inclusion complexation. Menthol was used as a model fragrance/flavor molecule and we have electrospun poly(ethylene oxide) (PEO) nanofibers containing cyclodextrin-menthol inclusion complexes (CD-menthol-IC). We used two different solvent systems; water and water:ethanol and three types of CDs; $\alpha-C D, \beta-C D$ and $\gamma-C D$ in order to find the optimal performance for the stabilization of menthol at high temperatures. We observed that the solvent system used for electrospinning process and the types of CDs $(\alpha-C D, \beta-C D$ and $\gamma-C D)$ are very important to obtain $\mathrm{CD}$-menthol-IC which ultimately determines the durability and temperature stability of menthol in the PEO nanofibrous web. We found out that it is better to use water rather than the water:ethanol solvent system for the inclusion complexation and additionally $\beta-C D$ and $\gamma-C D$ are most favorable choices since they are able to form complexation with menthol in the water solvent system. Despite the high volatility nature of menthol, our results demonstrated that the stability and temperature release of menthol was sustained to a very high and a broad temperature range $\left(100^{\circ} \mathrm{C}-250^{\circ} \mathrm{C}\right)$ for PEO nanowebs containing $\mathrm{CD}$-menthol-IC whereas the PEO nanofibers without $C D$ and without $C D$-menthol complex could not preserve menthol even during storage. In brief, the results are very encouraging and open up for a variety of new exciting possibilities for the development of multi-functional electrospun nanofibers containing cyclodextrin inclusion complexes.
\end{abstract}

Keywords: Cyclodextrin, Electrospinning, Poly(Ethylene Oxide) (PEO), Menthol, Nanofiber, Inclusion Complex.

\section{INTRODUCTION}

Electrospinning of nanofibers containing cyclodextrins (CD) and/or cyclodextrin inclusion complexes (CD-ICs) is attractive for both fundamental and applied interest since nanofibers with specific functions can be produced. ${ }^{1-11}$ Electrospinning has evolved as a versatile and costeffective technique for producing functional nanofibers from a wide variety of materials including for example; polymers, polymer blends, sol-gels, composites, etc. ${ }^{12-14}$ Electrospun nanofibers/nanowebs have several unique characteristics such as a large surface-to-volume ratio, pore sizes in the nano range and moreover, it is fairly easy to improve the functionality of the nanofibers by incorporating additives into the nanofibers during the electrospinning process. ${ }^{12-15}$ The functionalization

\footnotetext{
*Author to whom correspondence should be addressed
}

of nanofibers with cyclodextrin inclusion complexes (CDICs) is extremely attractive since such nanowebs containing $\mathrm{CD}$ complexes will have unique characteristics that can broaden the applications of cyclodextrins and nanofibers in the areas of filters, textiles, medical, packaging, etc.

Cyclodextrins $(\mathrm{CD})$ are cyclic oligosaccharides consisting of $\alpha(1,4)$-linked glucopyranose units having a toroidshaped molecular structure. The most common natural $\mathrm{CD}$ types are $\alpha-\mathrm{CD}, \beta-\mathrm{CD}$ and $\gamma-\mathrm{CD}$ which have 6 , 7 , and 8 glucopyranose units in the cyclic ring structure, respectively (Fig. 1). ${ }^{16} \mathrm{CDs}$ can form non-covalent inclusion complexes (CD-ICs) with various molecules by hosting guest molecules inside their cavity. ${ }^{16-20}$ The formation and the stability of the CD-ICs depend on many factors such as the size/shape match and the binding forces (hydrophobic interactions, the van der Waals attractions, the hydrogen bonding, and the electrostatic interactions) between the $\mathrm{CD}$ host and the guest molecules, and the chemical environment (solvent, $\mathrm{pH}$, temperature, etc.). ${ }^{19-210}$ 


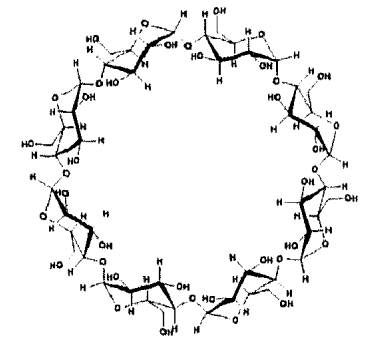

(a)

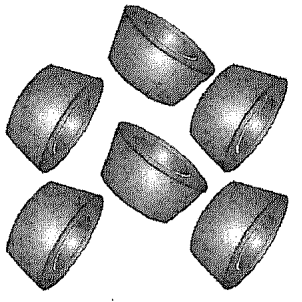

(d)

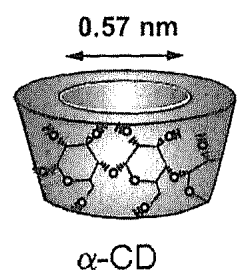

(b)
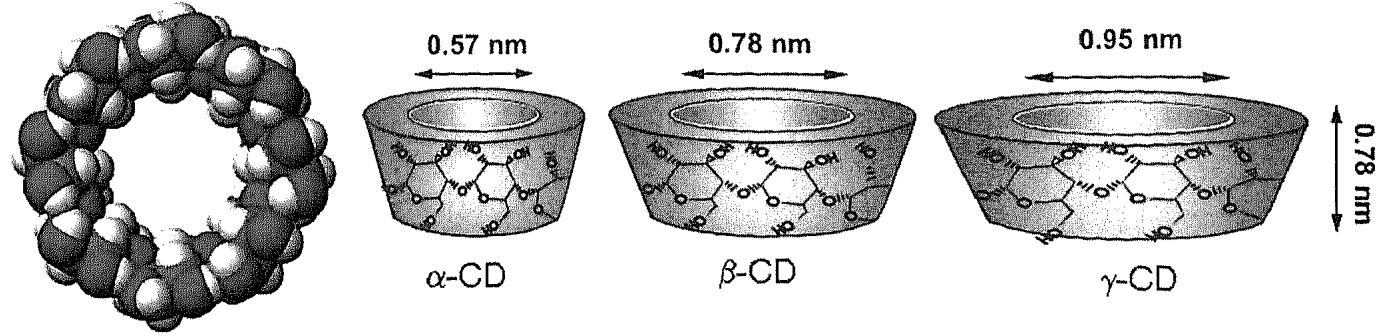

(c)

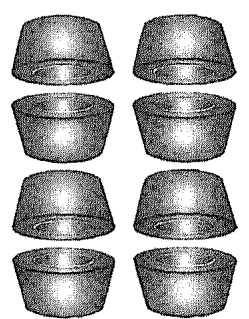

(e)

Fig. 1. (a) Chemical structure of $\gamma-\mathrm{CD}$, (b) 3-D structure of $\gamma-\mathrm{CD}$ and (c) approximate dimensions of $\alpha-\mathrm{CD}, \beta-\mathrm{CD}, \gamma-\mathrm{CD} .{ }^{16}$ Schematic representation of packing structures of (d) cage-type and (e) channel-type $\mathrm{CD}$ crystals.

Therefore, different types of CDs $(\alpha-\mathrm{CD}, \beta-\mathrm{CD}, \gamma-\mathrm{CDs}$ and chemically modified CDs) show different capability to form inclusion complexes with the same host molecule and the resulting CD-ICs have different stability. When the CD-ICs are formed, the functionality of the guest molecules is altered when included in the CD cavity, and furthermore the $C D$ cavity assists to stabilize/protect the guest molecules and control/sustain their delivery. ${ }^{16-18} \mathrm{CDs}$ are natural, nontoxic and slowly biodegradable molecules, and consequently the CDs are used in the development of functional materials in a number of areas such as pharmaceuticals (enhancement of drug solubility and stability, bioavailability, controlled drug delivery, reduction of drug toxicity, etc.), food science (stabilization of volatile or unstable flavors, masking/removal of unwanted tastes and odor, etc.), cosmetics and home/personal care products (releasing fragrances and masking unpleasant odor, etc.), and textiles (stabilization and control release of textile additives, etc.). ${ }^{16-18}$

Materials containing additives such as fragrances, flavors, antimicrobials and drugs are faced with significant problems such as the short shelf-life that arise due to the high volatility or instability nature of these additives. Cyclodextrins are however very effective for the stabilization and controlled/sustained release of these functional additives. ${ }^{16-18}$ Therefore, electrospun nanofibers containing inclusion complexes of $\mathrm{CD}$ with such additives would have functional characteristics with respect to the stability and controlled/sustained release of the fragrances, flavors, antimicrobials and drugs, etc. Very recently, we have reported the electrospinning of the polystyrene (PS) nanofibers ${ }^{8}$ and poly(methyl methacrylate) (PMMA) nanofibers ${ }^{9}$ containing cyclodextrin-inclusion complexes (CD-ICs). The incorporation of CD-ICs of allyl isothiocyanate ${ }^{10}$ (antimicrobial compound) and hydroxycamptothecin ${ }^{11}$ (drug molecule) into nanofiber matrix for the purpose of stability and controlled release of these additives were also reported very recently by other researchers.

In this study, our goal is to fabricate functional electrospun nanofibers containing durable and stable fragrances/ flavors molecules facilitated by cyclodextrin inclusion complexation. Menthol was used as a model fragrance/flavor additive and we have electrospun poly(ethylene oxide) (PEO) nanofibers containing cyclodextrin-menthol inclusion complexes (CD-menthol-IC). Two different solvent systems, water and water:ethanol were used and three type of CDs; $\alpha-\mathrm{CD}, \beta-\mathrm{CD}$ and $\gamma-\mathrm{CD}$ were tested in the electrospinning process to find the optimal performance for the stabilization of menthol at high temperatures. Our results demonstrate that the solvent system used for electrospinning process and the type of $\mathrm{CDs}(\alpha-\mathrm{CD}, \beta-\mathrm{CD}, \gamma-\mathrm{CD})$ are very important to obtain $C D$-menthol-IC which ultimately determines the durability and temperature stability of menthol in the polymeric nanofibrous matrix.

\section{EXPERIMENTAL DETAILS}

\subsection{Materials}

Poly(ethylene oxide) (PEO, $\mathrm{Mw} \sim 900,000$ ), ethanol (absolute, HPLC grade, $\geq 99.8 \%$ ) and menthol (99\%) were purchased from Sigma-Aldrich. The water used as solvent for the electrospinning was ultrapure MilliQ water. The alpha-, beta- and gamma-cyclodextrins ( $\alpha-\mathrm{CD}, \beta-\mathrm{CD}$ and $\gamma-\mathrm{CD}$ ) were obtained from Wacker Chemie AG, Germany. All the materials were used as-received without any purification. 


\subsection{Preparation of the Solutions}

Two different solvent systems; water and water:ethanol $(2: 1, \mathrm{v} / \mathrm{v})$ were used for the electrospinning of the PEO nanofibers. In water system, menthol and the CDs $(\alpha-\mathrm{CD}$, $\beta$-CD and $\gamma$-CD) were mixed in water for $1 \mathrm{~h}$ at $50^{\circ} \mathrm{C}$. The solutions were cooled down to room temperature (RT) and stirred for additional $6 \mathrm{~h}$. In the case of $\beta-\mathrm{CD}$ and $\gamma-\mathrm{CD}$ a suspension was obtained indicating an inclusion complexation between $\mathrm{CD}$ and menthol whereas the solution was clear for $\alpha$-CD. After that, PEO was added to $\mathrm{CD}$-menthol solutions and stirred for additional $18 \mathrm{~h}$ and the resulting solutions were electrospun. The $\mathrm{PEO} / \beta-\mathrm{CD}$ menthol and $\mathrm{PEO} / \gamma$-CD-menthol solutions were suspension whereas $\mathrm{PEO} / \alpha$-CD-menthol solution was clear.

In water:ethanol system, menthol and the $\mathrm{CDs}(\alpha-\mathrm{CD}$, $\beta-C D$ and $\gamma-C D)$ were mixed in water:ethanol $(2: 1, v / v)$ for $2 \mathrm{~h}$ at RT. In all cases the solutions were clear and no precipitation or turbidity was observed. PEO was added to $\mathrm{CD}$-menthol solutions and stirred for additional $22 \mathrm{~h}$ and then electrospun. The PEO/CD-menthol solutions kept their clarity after the addition of PEO. For comparison, $\mathrm{PEO} /$ menthol solution without $\mathrm{CD}$ was also prepared with the same conditions and electrospun.

The PEO concentration was first optimized in order to obtain bead-fee nanofibers. We found that the PEO concentration of $4 \%$ and $3 \%(\mathrm{w} / \mathrm{v})$ in water and water:ethanol, respectively, was optimal for producing uniform bead-free nanofibers, therefore, we kept the PEO concentration same when we use $C D$-menthol mixtures. The \% weight of menthol and CDs were adjusted which corresponds to the assumption that each type of CD forms 1:1 (molar ratio) inclusion complex with menthol. For water:ethanol system, the \% weight of the CDs were kept constant (\%25 (w/w), with respect to PEO) and the \% weight of the menthol was adjusted accordingly. In the case of the water system, the $\%$ weight of the menthol was kept constant (\%5 (w/w), with respect to $\mathrm{PEO}$ ) and the \% weight of the CDs were adjusted accordingly. The contents of the electrospun solutions were summarized in Table I.

\subsection{Electrospinning}

The solutions were placed in a $3 \mathrm{ml}$ syringe fitted with a stainless steel metallic needle with an inner diameter of $0.6 \mathrm{~mm}$. The syringe was fixed horizontally on the syringe pump (KDS 101, KD Scientific) and the electrode of the high voltage power supply (Spellman, MP Series) was clamped to the metal needle tip. The electrospinning parameters were set as follows: feed rate of the solution = $1 \mathrm{ml} / \mathrm{h}$, applied voltage $=15 \mathrm{kV}$, tip-to-collector distance $=$ $15 \mathrm{~cm}$. A grounded stationary rectangular metal collector $(15 \mathrm{~cm} \times 20 \mathrm{~cm})$ covered by a piece of clean aluminum foil was used for the fiber deposition. The complete electrospinning apparatus was enclosed in a glass box and the electrospinning of the fibers was carried out at RT. The obtained nanowebs were dried at RT under the suction hood for $24 \mathrm{~h}$ to let the uncomplexed menthol evaporate and to remove any present residual solvent.

\subsection{Characterizations}

The diameter and the morphologies of the electrospun nanofibers were examined by high resolution scanning electron microscopy (SEM) (FEI, Nova 600 NanoSEM). 2-D X-ray diffraction (XRD) data for the nanowebs were collected using a Stoe Stadi $\mathrm{P}$ diffractometer applying $\mathrm{Cu} K \alpha$ radiation at a range of $2 \theta=5-30^{\circ}$. Some of the $\mathrm{PEO} / \mathrm{CD}$-menthol nanowebs were shipped to Middle East Technical University (Ankara, Turkey) for the direct pyrolysis mass spectrometry (DP-MS) analyses, and in all cases the samples were analyzed around 10 days after their production. DP-MS system consisting of a Waters Quattro Micro GC tandem MS with an EI ion source and a mass range of $10-1500 \mathrm{Da}$, was coupled with a direct insertion probe $\left(\mathrm{T}_{\max }=650^{\circ} \mathrm{C}\right)$, and $0.010 \mathrm{mg}$ samples were

Table I. The solution compositions and the morphological characteristics of the electrospun nanofibers.

\begin{tabular}{|c|c|c|c|c|c|c|c|}
\hline Solutions & $\begin{array}{c}\text { Solution } \\
\text { appearance }\end{array}$ & Solvent $(v / v)$ & $\% \operatorname{PEO}^{a}(w / v)$ & $\begin{array}{c}\% \mathrm{CD}^{b} \\
\text { type }(\mathrm{w} / \mathrm{w})\end{array}$ & $\begin{array}{c}\% \text { menthol }^{b} \\
(\mathrm{w} / \mathrm{w})\end{array}$ & $\begin{array}{l}\text { Fiber diameter } \\
\text { range }(\mathrm{nm})\end{array}$ & $\begin{array}{l}\text { Fiber } \\
\text { morphology }\end{array}$ \\
\hline PEO & Clear & $\mathrm{H}_{2} \mathrm{O} / \mathrm{EtOH}(2 ; 1)$ & 3 & - & - & $130-265$ & Nanofibers \\
\hline $\mathrm{PEO} /$ menthol & Clear & $\mathrm{H}_{2} \mathrm{O} / \mathrm{EtOH}(2: 1)$ & 3 & - & 3.3 & $150-385$ & Nanofibers \\
\hline $\mathrm{PEO} / \alpha-\mathrm{CD}$-menthol & Clear & $\mathrm{H}_{2} \mathrm{O} / \mathrm{EtOH}(2: 1)$ & 3 & $25 \%, \alpha-\mathrm{CD}$ & 4 & $100-330$ & Nanofibers with few beads \\
\hline $\mathrm{PEO} / \beta$-CD-menthol & Clear & $\mathrm{H}_{2} \mathrm{O} / \mathrm{EtOH}(2: 1)$ & 3 & $25 \%, \beta-\mathrm{CD}$ & 3.3 & $105-265$ & Nanofibers \\
\hline $\mathrm{PEO} / \gamma$-CD-menthol & Clear & $\mathrm{H}_{2} \mathrm{O} / \mathrm{EtOH}(2: 1)$ & 3 & $25 \%, \gamma-\mathrm{CD}$ & 3 & $75-250$ & Nanofibers \\
\hline PEO & Clear & $\mathrm{H}_{2} \mathrm{O}$ & 4 & - & - & $120-275$ & Nanofibers \\
\hline $\mathrm{PEO} / \alpha$-CD-menthol & Clear & $\mathrm{H}_{2} \mathrm{O}$ & 4 & $31 \%, \alpha-\mathrm{CD}$ & 5 & $50-195$ & $\begin{array}{l}\text { Nanofibers with } \\
\text { Few elongated beads }\end{array}$ \\
\hline $\mathrm{PEO} / \beta$-CD-menthol & Suspension & $\mathrm{H}_{2} \mathrm{O}$ & 4 & $36 \%, \beta-\mathrm{CD}$ & 5 & $90-250$ & $\begin{array}{l}\text { Nanofibers with very } \\
\text { Few elongated beads }\end{array}$ \\
\hline $\mathrm{PEO} / \gamma$-CD-menthol & Suspension & $\mathrm{H}_{2} \mathrm{O}$ & 4 & $41 \%, \gamma-\mathrm{CD}$ & 5 & $60-235$ & $\begin{array}{l}\text { Nanofibers with very } \\
\text { Few elongated beads }\end{array}$ \\
\hline
\end{tabular}

a with respect to solvent; ${ }^{b}$ with respect to polymer (PEO). 
pyrolyzed in the quartz sample vials at a heating rate of $10{ }^{\circ} \mathrm{C} / \mathrm{min}$.

\section{RESULTS AND DISCUSSION}

Table I summarizes the solution compositions and the morphological characteristics of the resulting electrospun nanofibers. The SEM images of the nanowebs obtained from water:ethanol $(2: 1, \mathrm{v} / \mathrm{v})$ and water solvent systems are depicted in Figures 2 and 3, respectively. When the water:ethanol $(2: 1, \mathrm{v} / \mathrm{v})$ solvent system was used, the obtained nanofibers are bead-free except for $\mathrm{PEO} / \alpha$-CD-menthol. In the case of the water solvent system, the $\mathrm{PEO} / \mathrm{CD}$-menthol nanofibers are to a large extent uniform along with very few elongated beaded structures. The fiber diameters range from $50 \mathrm{~nm}$ to $385 \mathrm{~nm}$ for the obtained nanowebs. In brief, no significant morphological differences were observed for PEO/CDmenthol nanofibers when compared to pure PEO nanofibers except for $\mathrm{PEO} / \alpha$-CD-menthol nanofibers obtained from water:ethanol system.

The 2-D XRD studies were performed for the pure menthol and the nanowebs of PEO, PEO/menthol and the PEO/CD-menthol (Figs. 4-5). Menthol is a crystalline material having salient peaks centered at $2 \theta \cong 5.6^{\circ}, 18.85^{\circ}$ and $22^{\circ}$ (Fig. 4(i)). PEO is a semi-crystalline polymer with diffraction peaks at $2 \theta=19^{\circ}$ and $23^{\circ}$ (Fig. 4(ii)). The XRD pattern of $\mathrm{PEO} /$ menthol nanowebs is very similar to $\mathrm{PEO}$ showing no diffraction for crystalline menthol peak suggesting that either menthol is in amorphous state in the fiber matrix or menthol has been already evaporated from the matrix.

CDs are crystalline and have crystal structures referred to cage-type (Fig. 1(d)) and channel-type (Fig. 1(e)). ${ }^{21-22}$ The as-received uncomplexed CDs have cage-type packing, on the other hand, in general, the CD molecules adopt channel-type packing when they form inclusion complexation with host molecules. ${ }^{22}$ In X-ray diffraction (XRD) pattern, $\alpha$-CD with the channel-type packing structure show two salient peaks centered at $2 \theta \cong 13^{\circ}$ and $20^{\circ} .{ }^{23}$ Channeltype $\gamma$-CD has one major peak at $2 \theta \cong 7.5^{\circ}$ with minor reflections at $2 \theta \cong 14^{\circ}, 15^{\circ}, 16^{\circ}, 17^{\circ}$ and $22^{\circ} . .^{24}$ The typical channel-type $\beta$-CD has two major peaks at $2 \theta \cong 12^{\circ}$ and $18^{\circ} .{ }^{25}$

For the $\mathrm{PEO} / \beta$-CD-menthol and the $\mathrm{PEO} / \gamma-\mathrm{CD}$-menthol nanowebs obtained from water:ethanol solvent solution no diffraction peaks are detected (Figs. 4(v and vi)) that can be associated with $\mathrm{CDs}$ and the observed diffraction patterns, which is similar to that for PEO, suggest that CDs are predominantly present as an amorphous state in the polymer matrix. However, in the case of $\mathrm{PEO} / \alpha$ CD-menthol nanofibers, characteristic peaks, though weak, of $\alpha-\mathrm{CD}$ channel structure are observed at $2 \theta \cong 3^{\circ}$ and $20^{\circ}$ (Fig. 4(iv)) suggesting that $\alpha$-CD-menthol inclusion complexes may be incorporated in the PEO nanofibers. For PEO/CD-menthol nanowebs obtained from the water solvent system, characteristic peaks of $\mathrm{CD}$ channel structure are observed for $\mathrm{PEO} / \gamma-\mathrm{CD}$-menthol and $\mathrm{PEO} / \beta$ CD-menthol nanofibers, respectively (Figs. 5(ii and iii)). although the peaks are quite weak for $\mathrm{PEO} / \beta$-CD-menthol.
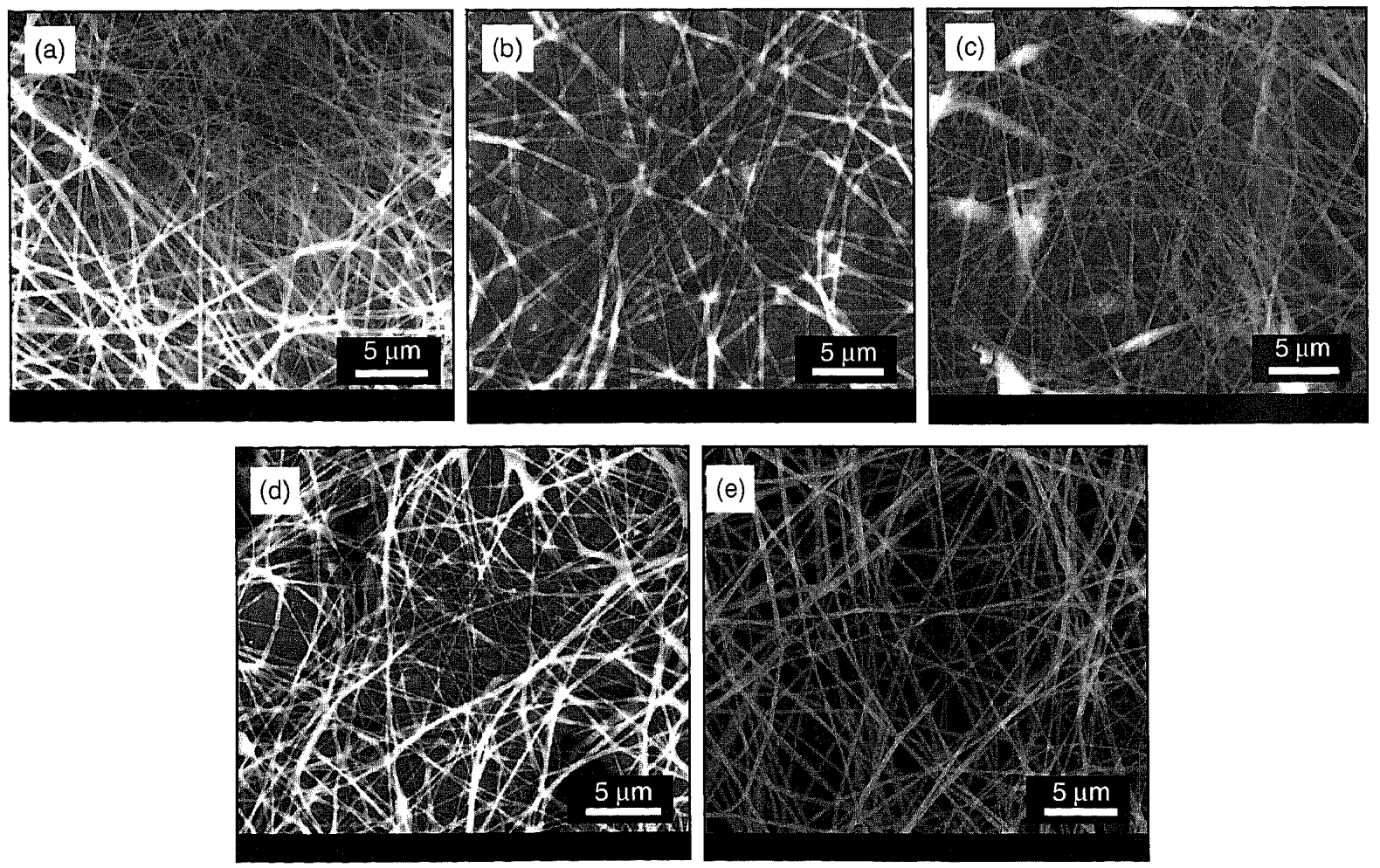

Fig. 2. SEM images of nanofibers electrospun from water/ethanol $(2: 1, \mathrm{v} / \mathrm{v})$ solvent system (a) PEO (b) PEO/menthol, (c) PEO/ $\alpha$-CD-menthul. (d) $\mathrm{PEO} / \beta$-CD-menthol and (e) $\mathrm{PEO} / \gamma$-CD-menthol. 

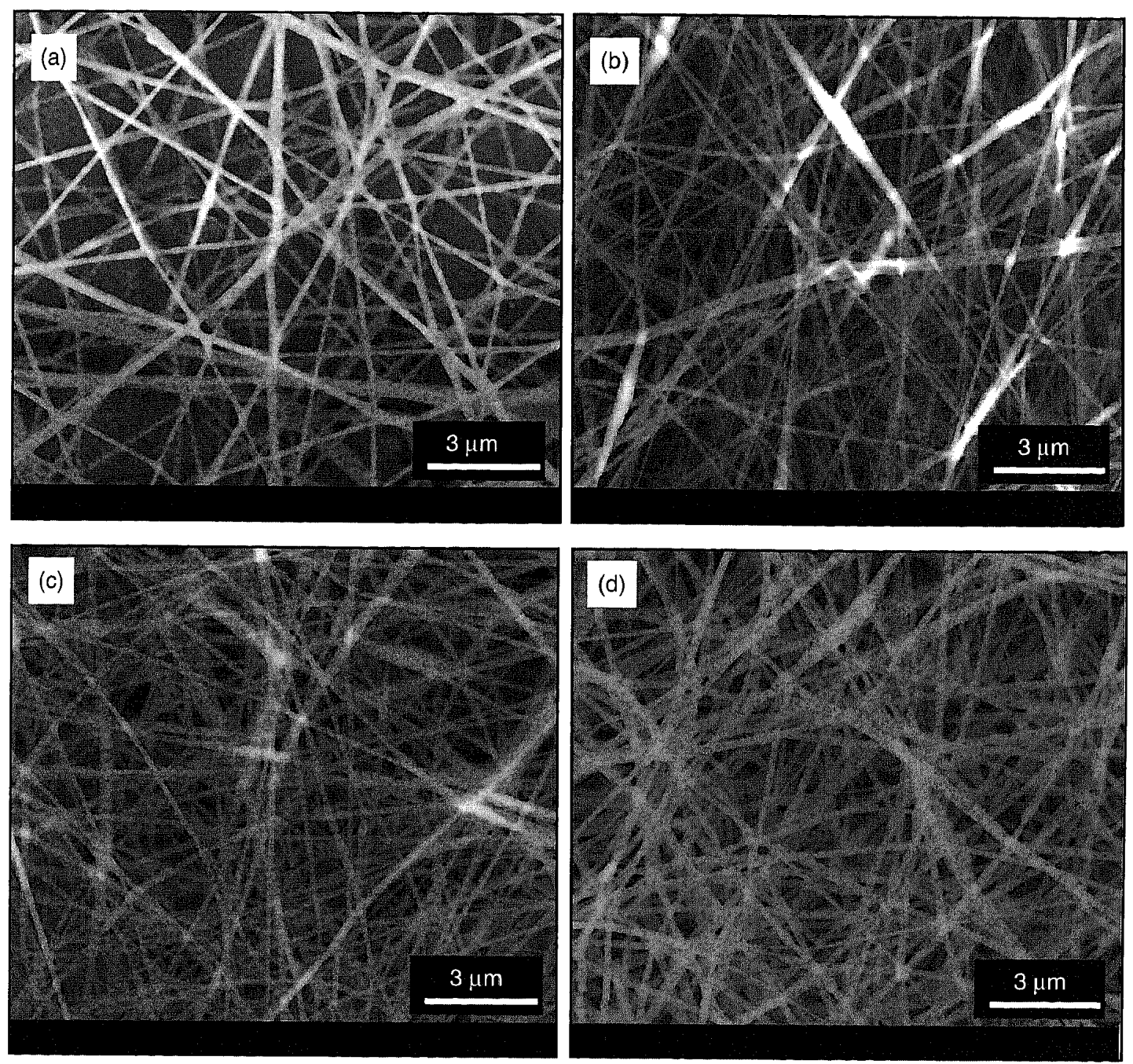

Fig. 3. SEM images of nanofibers electrospun from water solution (a) PEO, (b) PEO/ $\alpha$-CD-menthol, (c) PEO/ $\beta$-CD-menthol and (d) PEO/ $\gamma$-CDmenthol.

In the case of the $\mathrm{PEO} / \alpha-\mathrm{CD}$-menthol system, no significant diffraction peaks are detected for the channel structure (Fig. 5(i)). These findings indicate that $\beta$-CD and $\gamma$-CD formed inclusion complexes with menthol whereas $\alpha-C D$ did not when water was used as a solvent system. These findings are very well correlated with our visual observation of the solutions where it was observed that when $\beta-\mathrm{CD}$ and $\gamma-\mathrm{CD}$ was mixed with menthol precipitation occurred due to inclusion complexation whereas the solution of $\alpha-\mathrm{CD}$ was clear signifying that the complexation did not form.

In brief, the XRD studies of PEO/CD-menthol nanowebs produced from the water solvent system thus reveal the incorporation of CD-menthol inclusion complex in PEO nanofibers for $\beta-C D$ and $\gamma-C D$ since $C D$ molecules adopt channel-type packing structures when they form inclusion complexes. ${ }^{22}$ However in the case of $\mathrm{PEO} / \alpha-\mathrm{CD}$-menthol no distinct XRD diffraction patterns were observed for any type of $C D$ crystal aggregates which indicates that no complexation occurred for $\alpha-C D$ with menthol. In the case of the water:ethanol solvent system, the CD channel-type packing was only detected for $\mathrm{PEO} / \alpha-\mathrm{CD}$-menthol nanowebs. Furthermore, for all $\mathrm{PEO} / \mathrm{CD}$-menthol nanowebs there was no indication of any CD cage-type structures since no corresponding peaks for this packing appeared in the XRD diffractograms.

The possibility of complexation between PEO and CDs was also considered, however, we found that PEO and CDs did not form any such complexation under the experimental conditions explored in this system. ${ }^{5}$ This further supports that the PEO does not interfere with the inclusion complexation of menthol with the CD molecules. Hence, the specific choice of the polymer matrix is of utmost importance when the CD-IC functionalized nanofibers are produced by the electrospinning technique.

The XRD technique can, however, only provide indirect information by detection of channel-type packing of CDs signifying whether or not CD-menthol-IC is present in the PEO nanofibers. Therefore, we have also carried out direct pyrolysis mass spectrometry (DP-MS) experiments to further explore the presence of CD-menthol-IC and to investigate the stability of the menthol in the PEO nanowebs. Once complexed with the $\mathrm{CD}$ cavity, the evaporation of the volatile guest molecules shifts to higher temperatures due 


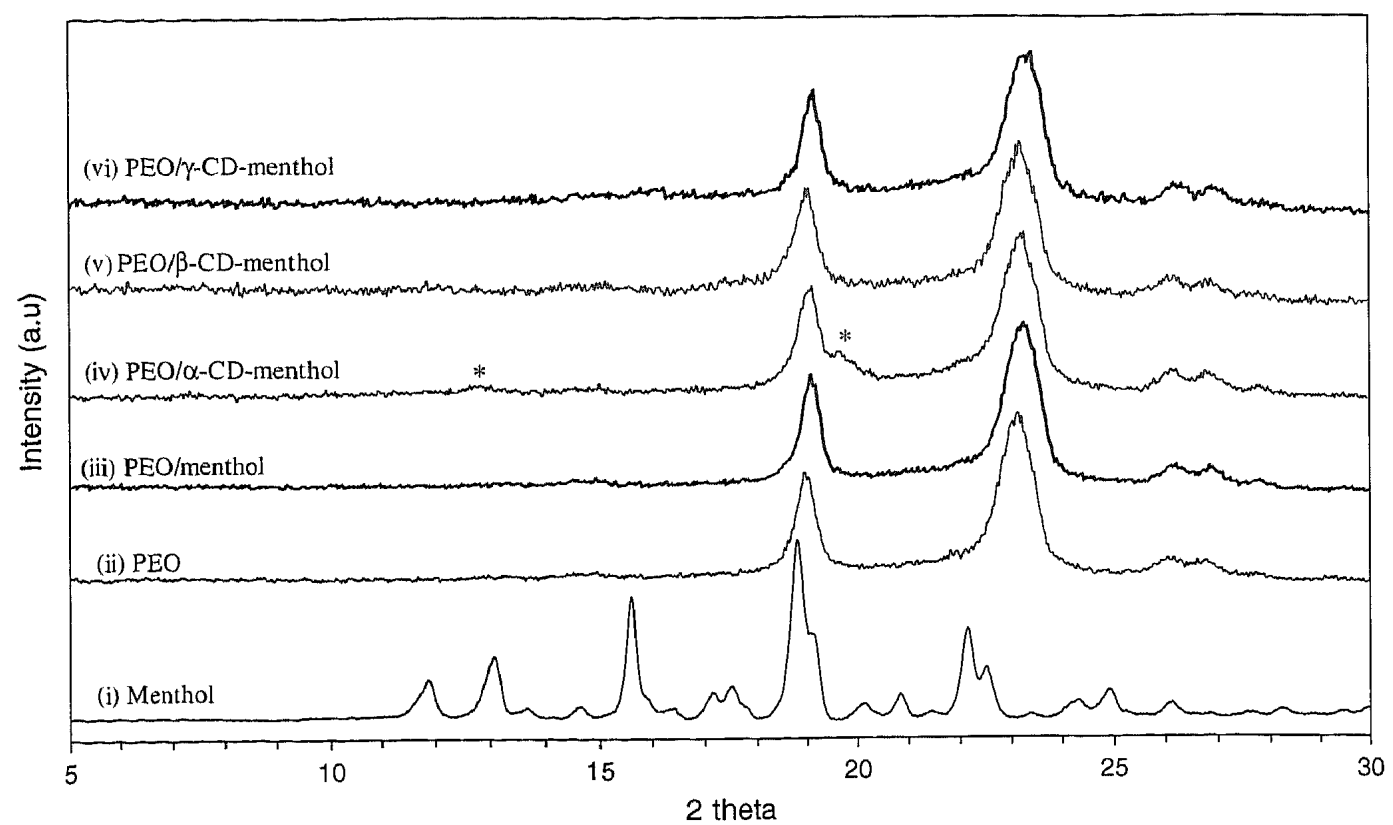

Fig. 4. 2-D XRD patterns of (i) pure menthol and electrospun nanowebs obtained from water/ethanol (2:1, v/v) system; (ii) PEO, (iii) PEO/menthol, (iv) $\mathrm{PEO} / \alpha$-CD-menthol, (v) PEO/ $\beta$-CD-menthol and (vi) $\mathrm{PEO} / \gamma$-CD-menthol.

to the strong interaction with the CD cavity. ${ }^{16-18}$ Hence, the DP-MS technique is a very useful technique for the characterization of the CD host-guest inclusion complexes. ${ }^{8,9,26}$ DP-MS allows separation of components as a function of their volatilities and/or thermal stabilities in the case of a multi-component system. However, pyrolysis mass spectra of a multi-component system, especially the ones involving polymers, are usually very complex due to the dissociative ionization processes and due to the fact that all fragments with the same mass to charge ratio contributes to the intensity of the same peak in the mass spectrum.
Therefore, in DP-MS analyses not only the detection of the certain mass components but also the variation of their yield as a function of temperature (i.e., the thermal evolution profile) is very important in order to determine the origin of the product. ${ }^{26-28}$

Firstly, DP-MS analysis of pure menthol was carried out for comparison. Under the high vacuum conditions for the DP-MS technique, the immediate release evolution profile of menthol testified the very volatile characteristics of menthol. The product yield was maximum at around room temperature and thereafter decreased

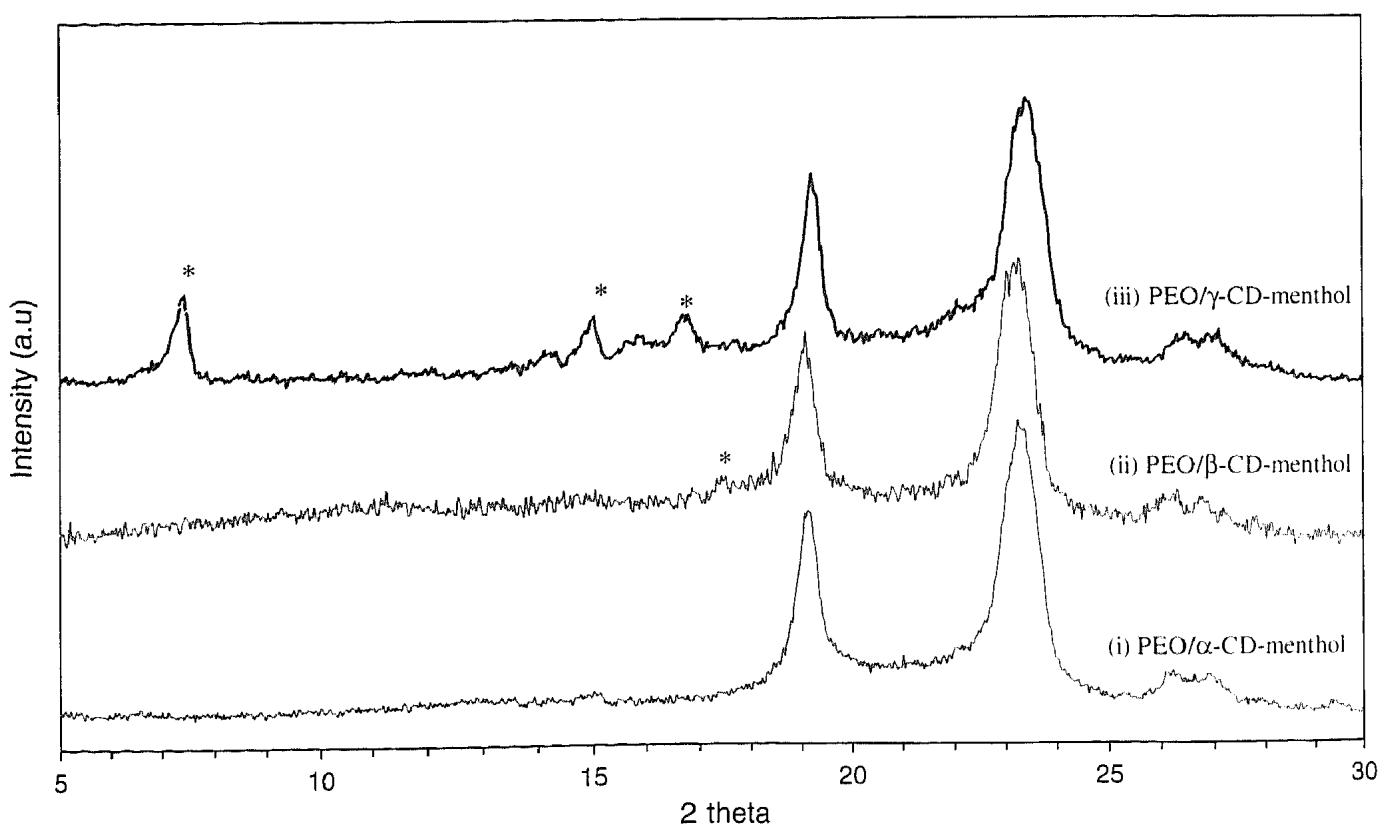

Fig. 5. 2-D XRD patterns of electrospun nanowebs obtained from water system; (i) PEO/ $\alpha$-CD-menthol, (ii) PEO/ $\beta$-CD-menthol and (iii) PEO/ $\gamma$-CD-menthol. 
steadily and disappeared totally (data not shown). The pyrolysis mass spectrum, with intense peaks at $\mathrm{m} / \mathrm{z}=$ $71,81,95,123$ and $138 \mathrm{Da}$ and a very weak molecular ion peak at $\mathrm{m} / \mathrm{z}=156 \mathrm{Da}$, is identical to the mass spectrum of menthol extracted from standard mass libraries.

Unfortunately, all the peaks in the mass spectrum of menthol are also present in those of PEO and CD, and those of CDs are also present in that of PEO. Yet, the temperature ranges where the thermal release and/or degradation of these compounds take place are quite distinct; for the PEO based products the maximum release occur above $400{ }^{\circ} \mathrm{C}$ and for those of $\mathrm{CDs}$ at around $370{ }^{\circ} \mathrm{C}$. Thus, identification and/or separation of components as a function of their volatilities and/or thermal stabilities are indeed possible. The total ion current (TIC; variation of total ion yield as a function of temperature) curve of $\mathrm{PEO} /$ menthol showed a single peak with a maximum at $405^{\circ} \mathrm{C}$ associated with decomposition of PEO and those of $\mathrm{PEO} / \mathrm{CD}$-menthol nanowebs obtained from water:ethanol system showed two peaks with maxima at around $372{ }^{\circ} \mathrm{C}$ and $405^{\circ} \mathrm{C}$ attributed to evolution of $\mathrm{CD}$ and PEO based products, respectively. No evidence for the presence of menthol was detected. As an example, the TIC curve and the pyrolysis mass spectra for $\mathrm{PEO} / \beta-\mathrm{CD}$-menthol in water:ethanol system are depicted in Figure 6(a). Four fragments are identified, in the temperature evolution profiles; $\mathrm{C}_{6} \mathrm{H}_{13} \mathrm{O}_{2}(\mathrm{~m} / \mathrm{z}=117 \mathrm{Da})$ corresponding to only PEO, $\mathrm{C}_{2} \mathrm{H}_{4} \mathrm{O}_{2}(\mathrm{~m} / \mathrm{z}=60 \mathrm{Da})$ corresponding to both $\mathrm{PEO}$ and $\mathrm{CD}$, and finally two products $\mathrm{C}_{5} \mathrm{H}_{11}$ yielding the base peak at $71 \mathrm{Da}$ and $\mathrm{C}_{10} \mathrm{H}_{18}(\mathrm{~m} / \mathrm{z}=138 \mathrm{Da})$ generated by loss of water from menthol, are compared in Figure $6(\mathrm{~b})$. The peaks at $\mathrm{m} / \mathrm{z}=71$ and $138 \mathrm{Da}$ in the mass spectra of $\mathrm{PEO}$ and $\mathrm{CDs}$ are assigned to $\mathrm{C}_{4} \mathrm{H}_{7} \mathrm{O}$ and $\mathrm{C}_{3} \mathrm{H}_{3} \mathrm{O}_{2}$, and $\mathrm{C}_{8} \mathrm{H}_{19} \mathrm{O}_{2}$ and $\mathrm{C}_{4} \mathrm{H}_{10} \mathrm{O}_{5}$, respectively. The $71 \mathrm{Da}$ peak was among the most intense peaks in the pyrolysis mass spectra of PEO but relatively weak in those of CDs. On the other hand $138 \mathrm{Da}$ peak was quite weak in the mass spectra of both PEO and CDs. During the pyrolysis of PEO/menthol only a single peak with a maximum at around $405^{\circ} \mathrm{C}$ was detected in the evolution profiles of all the selected fragments generated. The data indicate that the menthol was not present in the sample confirming the volatile nature of menthol which most probably evaporated even before the DP-MS analyses of the nanoweb. Again, a single peak was present in the evolution profiles of $\mathrm{C}_{6} \mathrm{H}_{13} \mathrm{O}_{2}$ diagnostic to $\mathrm{PEO}$ as expected for all the PEO/CD-menthol nanowebs. The two peaks present in the evolution profiles of products with $\mathrm{m} / \mathrm{z}$ values of 60,71 and $138 \mathrm{Da}$, with maxima at around 372 and $405^{\circ} \mathrm{C}$ and were directly assigned to CDs and PEO, respectively. The very weak peak detected at around $140{ }^{\circ} \mathrm{C}$ in the temperature evolution profiles of the $\mathrm{m} / \mathrm{z}=71$ and $138 \mathrm{Da}$ products for nanowebs involving $\alpha-\mathrm{CD}$ and $\gamma-\mathrm{CD}$ (being weaker for $\gamma-\mathrm{CD}$ ) was assigned to the evolution of menthol. For the nanoweb involving $\beta$-CD no such temperature evolution profiles were observed. Thus, single ion evolution profiles of characteristic $\mathrm{m} / \mathrm{z}$ products confirmed the lack of any significant amount of menthol being released in the nanowebs which thus indicate that the water-ethanol solvent system is not suitable for the inclusion complexation between $C D$ and menthol.

Also, in the case of the water solvent system no indication of menthol was detected for $\mathrm{PEO} / \alpha-\mathrm{CD}$ menthol nanoweb. However, the evolution of menthol was detected for the $\mathrm{PEO} / \beta-\mathrm{CD}$-menthol and $\mathrm{PEO} / \gamma-\mathrm{CD}$ menthol nanowebs (Fig. 7). The trends observed in the single ion evolution profiles of $\mathrm{C}_{6} \mathrm{H}_{13} \mathrm{O}_{2}(\mathrm{~m} / \mathrm{z}=117)$ and $\mathrm{C}_{2} \mathrm{H}_{4} \mathrm{O}_{2}(\mathrm{~m} / \mathrm{z}=60)$ corresponding to $\mathrm{PEO}$ and $\mathrm{CDs}$, respectively, are almost identical to those of the corresponding evolution profiles recorded for nanowebs in water-ethanol solvent system. Yet, in the evolution profiles of the products with $\mathrm{m} / \mathrm{z}$ values 71 and $138 \mathrm{Da}$, two peaks with maxima at 170 and $227^{\circ} \mathrm{C}$ and a single broad peak with maximum at $170{ }^{\circ} \mathrm{C}$ are observed for $\mathrm{PEO} / \beta-\mathrm{CD}$-menthol and $\mathrm{PEO} / \gamma$ $\mathrm{CD}$-menthol systems, respectively, and are associated with evolution of menthol confirming inclusion complexation in accordance with XRD findings and visual observations. The presence of two peaks in the temperature region which both are correlated to menthol release from the nanoweb involving $\beta-C D$, can directly be attributed to the presence of different interactions between menthol and $\beta-C D$ cavity. In addition, the release of menthol occurred at higher temperatures from $\mathrm{PEO} / \beta-\mathrm{CD}$-menthol nanoweb when compared to $\mathrm{PEO} / \gamma$-CD-menthol nanoweb suggesting that the interaction of menthol with $\beta$-CD cavity is much stronger when compared to $\gamma$-CD.

The DP-MS data thus demonstrated that PEO/CDmenthol nanowebs obtained from the water:ethanol solution system could not in general preserve volatile menthol molecules in significant amounts due to the lack of inclusion complexation between CDs and menthol. Yet, very weak menthol related peaks were detected at around $140{ }^{\circ} \mathrm{C}$ for $\mathrm{PEO} / \alpha-\mathrm{CD}$-menthol and $\mathrm{PEO} / \gamma-\mathrm{CD}$ menthol nanowebs confirming that a very small amount of inclusion complexation is present in the nanofibers. This finding suggests that the water-ethanol solvent system is not appropriate for the CD-menthol complexation. In the case of $\mathrm{PEO} / \mathrm{CD}$-menthol nanowebs produced from the water solvent system, the stability and sustained release of menthol at very high temperature ranges $\left(100-250^{\circ} \mathrm{C}\right.$ ) clearly reveal the presence of CD-menthol inclusion complexation in the $\mathrm{PEO} / \beta$-CD-menthol and $\mathrm{PEO} / \gamma$-CD-menthol nanowebs. On the contrary, the PEO nanofibers containing $\alpha$-CD could not preserve volatile menthol molecules since the inclusion complexation between $\alpha-C D$ and menthol did not form most likely due to inappropriate solvent system for complexation and lack of binding forces under the present experimental conditions. 
(a)
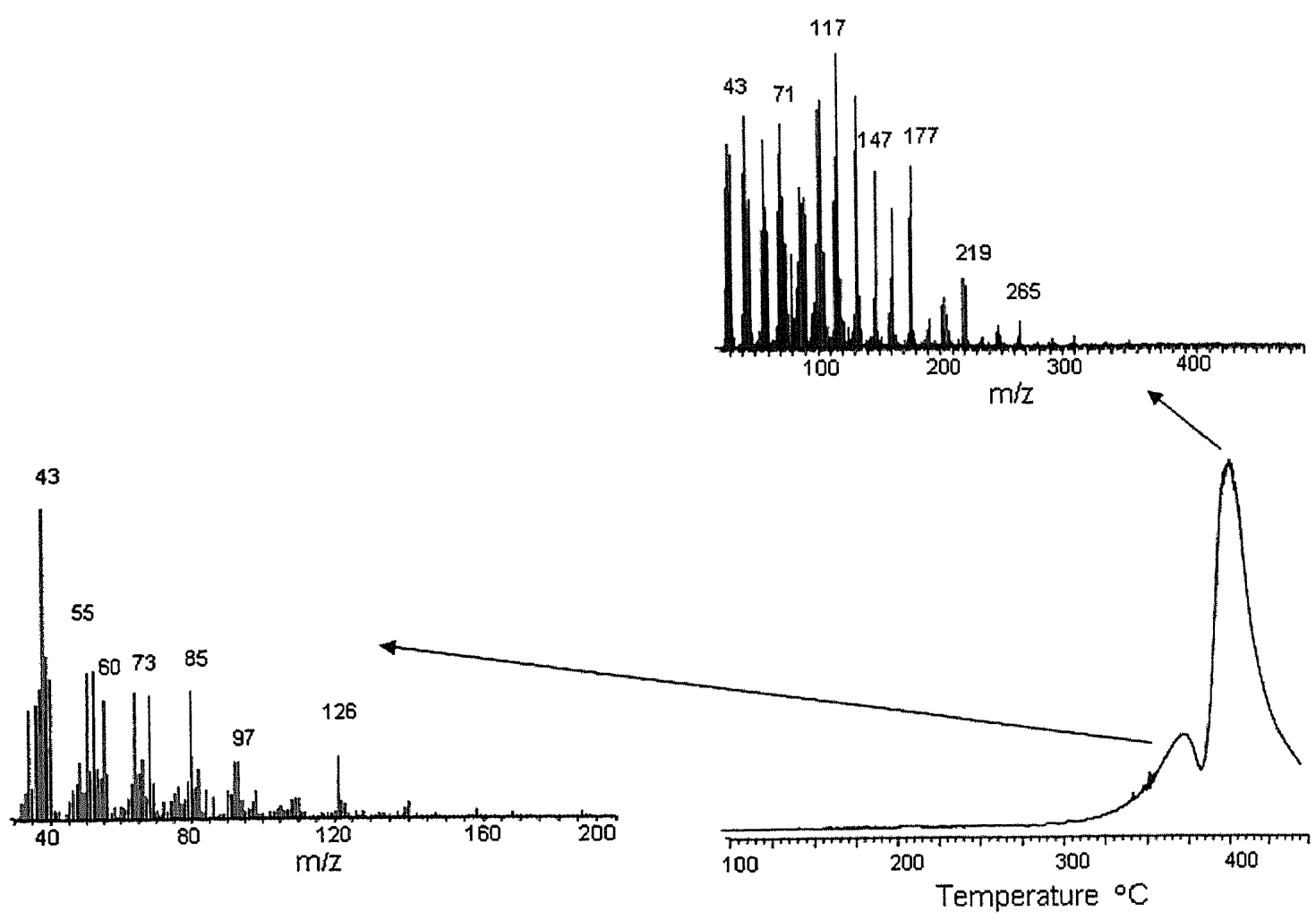

(b)
PEO
$\mathrm{m} / \mathrm{z}=117 \mathrm{Da}$

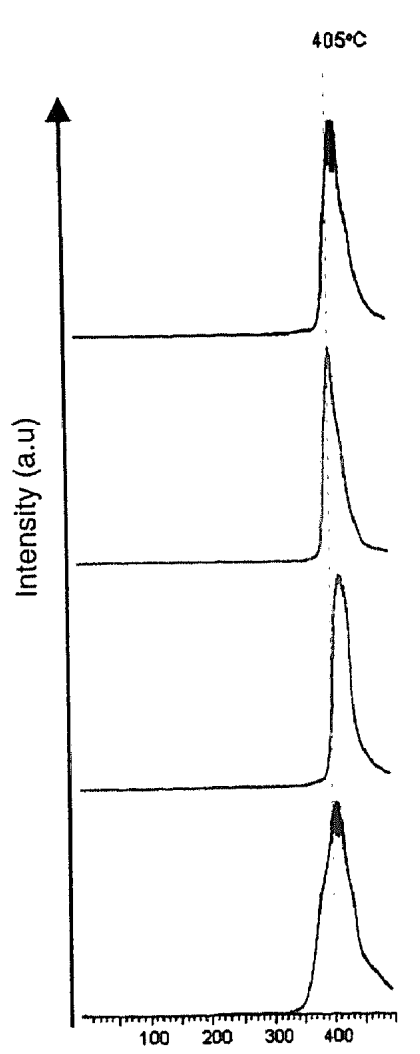

$P E O$ and $C D$ $\mathrm{m} / \mathrm{z}=60 \mathrm{Da}$
Menthol, PEO and CD $\mathrm{m} / \mathrm{z}=71 \mathrm{Da}$
Menthol, $P E O$ and $C D$ $\mathrm{m} / \mathrm{z}=138 \mathrm{Da}$

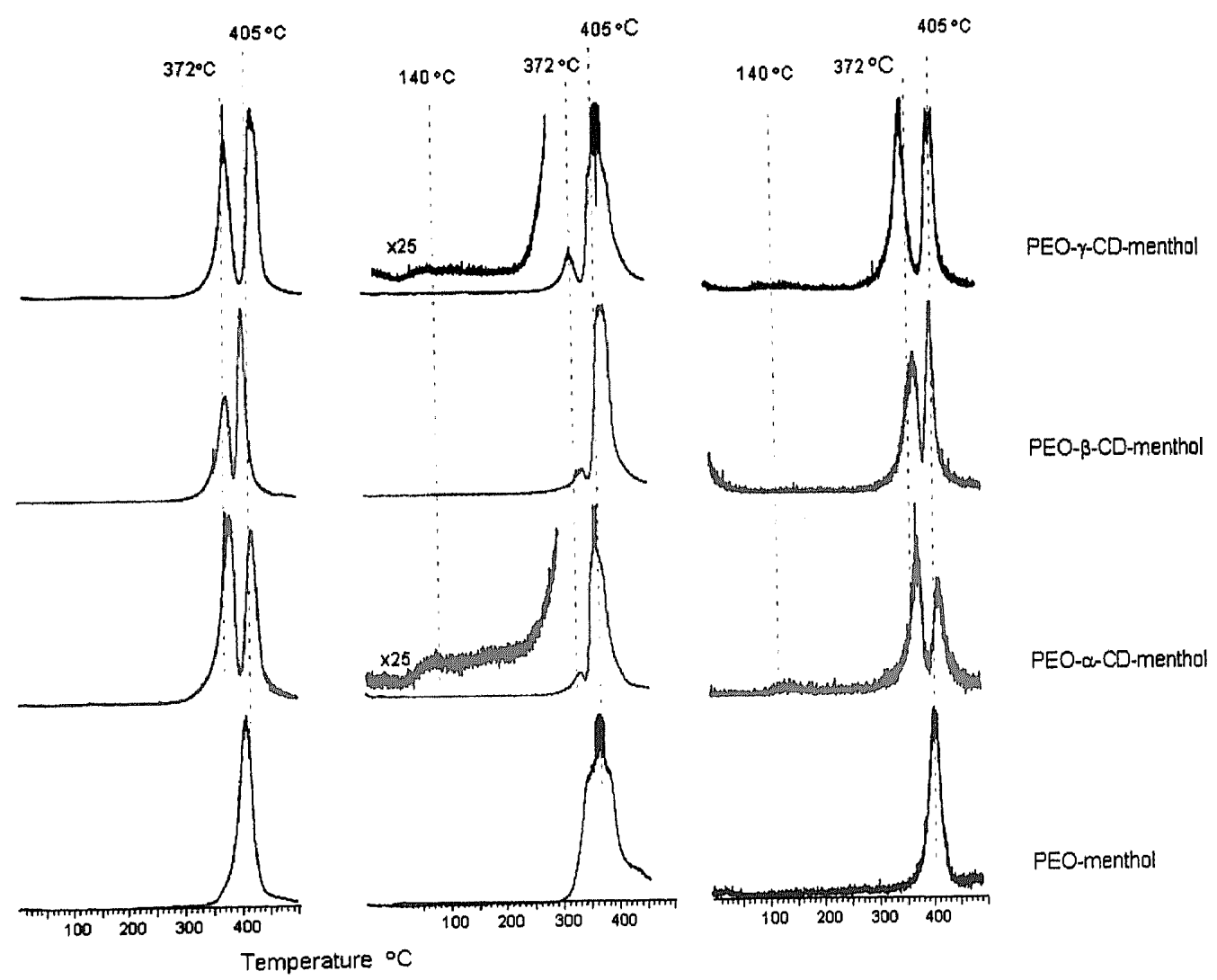

Fig. 6. The DP-MS data of the nanowebs produced from water:ethanol system. (a) The TIC curve and the mass spectra recorded at the peak maxima present in the TIC curve detected during the pyrolysis of PEO/ $\beta$-CD-menthol. (b) Evolution profiles of some characteristic fragment ions of each components; $\mathrm{C}_{6} \mathrm{H}_{13} \mathrm{O}_{2}(\mathrm{~m} / \mathrm{z}=117 \mathrm{Da})$ characteristic to only PEO, $\mathrm{C}_{2} \mathrm{H}_{4} \mathrm{O}_{2}(\mathrm{~m} / \mathrm{z}=60 \mathrm{Da})$ diagnostic for both $\mathrm{PEO}$ and $\mathrm{CD}$, and two products at $\mathrm{C}_{5} \mathrm{H}_{11}$ $(\mathrm{m} / z=71 \mathrm{Da})$ and $\mathrm{C}_{10} \mathrm{H}_{18}(\mathrm{~m} / \mathrm{z}=138 \mathrm{Da})$ diagnostic to PEO, $\mathrm{CD}$ and menthol. (Note: For clarity, the 71 Da evolution profile enlarged by a factor of 25 is also given for $\mathrm{PEO} / \alpha-\mathrm{CD}$-menthol and $\mathrm{PEO} / \gamma-\mathrm{CD}$-menthol). 
(a)

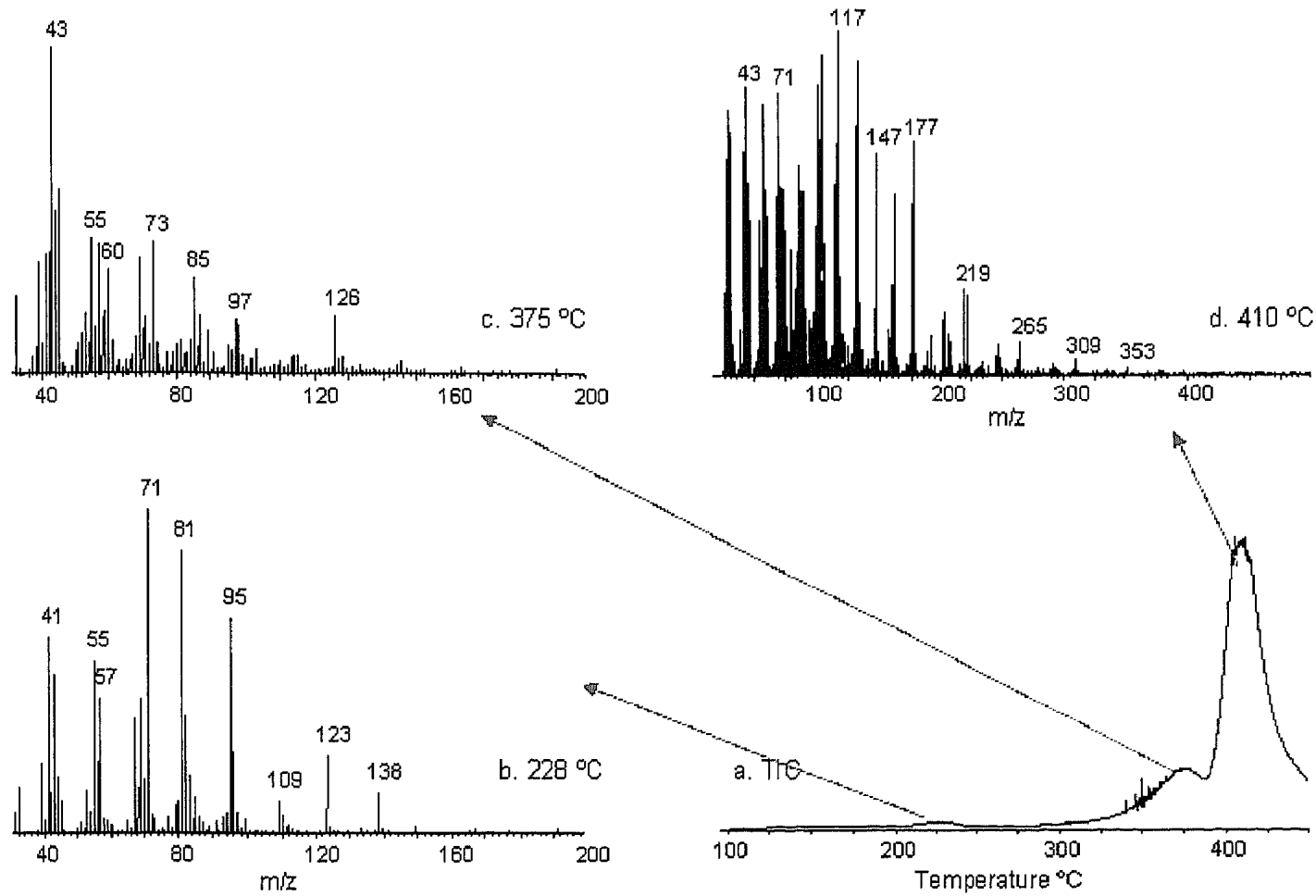

(b)

$$
\text { PEO }
$$

$\mathrm{m} / \mathrm{z}=117 \mathrm{Da}$

$P E O$ and $C D$

$m / z=60 \mathrm{Da}$

Menthol, $P E O$ and $C D$

Menthol, PEO and CD

$\mathrm{m} / \mathrm{z}=138 \mathrm{Da}$
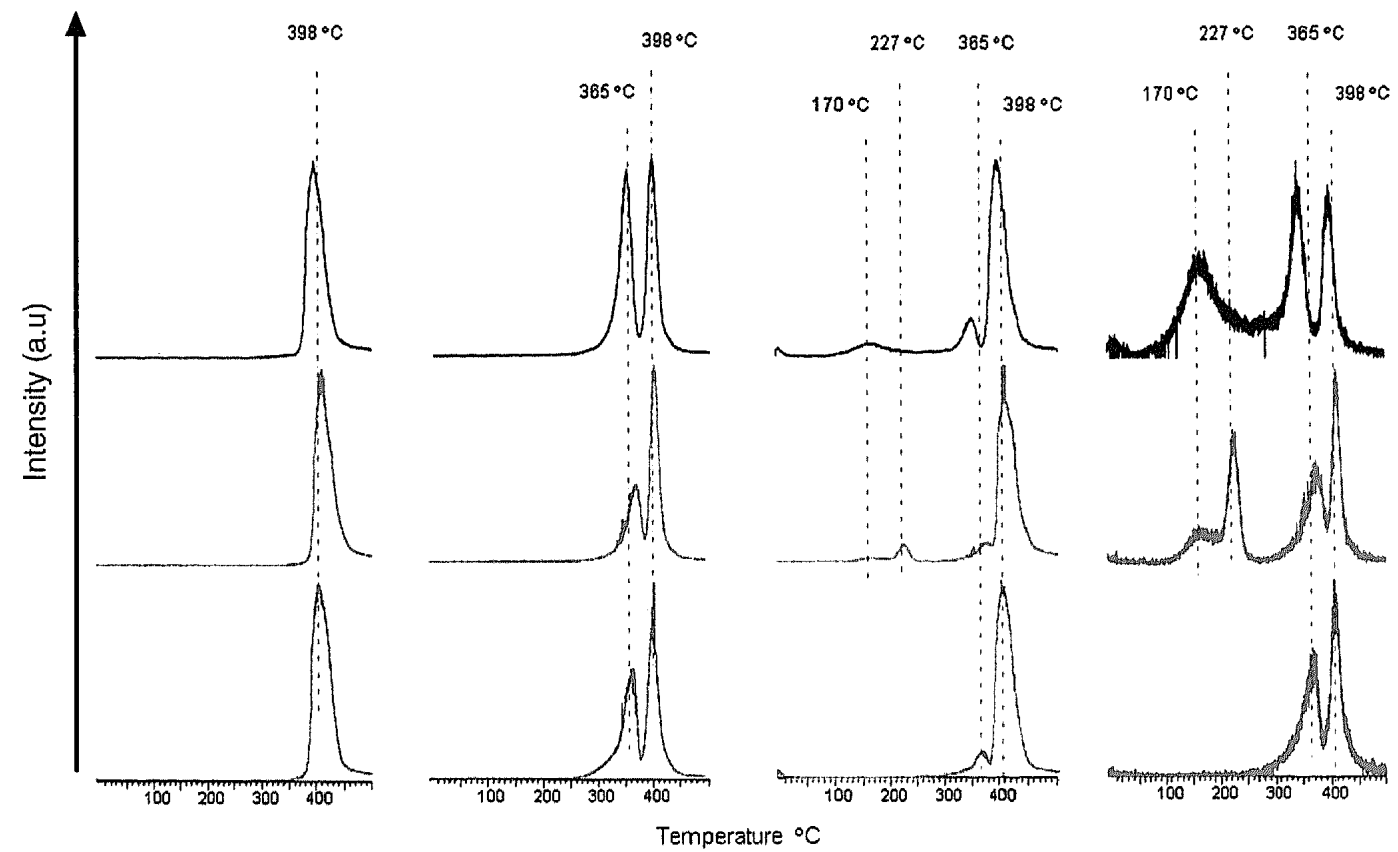

PEO/y-CD-menthol

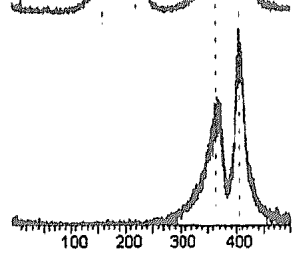

$P E O / \beta-C D-m e n t h o l$

PEO/a-CD-menthol

Fig. 7. The DP-MS data of the nanowebs produced from water system. (a) The TIC curve and the mass spectra recorded at the peak maxima present in the TIC curve detected during the pyrolysis of $\mathrm{PEO} / \beta$-CD-menthol. (b) Evolution profiles of some characteristic fragment ions of each components; $\mathrm{C}_{6} \mathrm{H}_{13} \mathrm{O}_{2}(\mathrm{~m} / \mathrm{z}=117 \mathrm{Da})$ characteristic to only PEO, $\mathrm{C}_{2} \mathrm{H}_{4} \mathrm{O}_{2}(\mathrm{~m} / \mathrm{z}=60 \mathrm{Da})$ diagnostic for both $\mathrm{PEO}$ and $\mathrm{CD}$, and two products at $\mathrm{C}_{5} \mathrm{H}_{11}(\mathrm{~m} / \mathrm{z}=71 \mathrm{Da})$ and $\mathrm{C}_{10} \mathrm{H}_{18}(\mathrm{~m} / \mathrm{z}=138 \mathrm{Da})$ diagnostic to $\mathrm{PEO}, \mathrm{CD}$ and menthol.

\section{CONCLUSION}

In conclusion, with the overall goal to fabricate functional nanofibers we have demonstrated that the cyclodextrinmenthol inclusion complexes (CD-menthol-ICs) can successfully be incorporated in PEO nanofibers by means of the electrospinning technique. It was observed that the complexation of menthol and CDs strongly depend on the solvent system and the type of CDs $(\alpha-, \beta$ - and $\gamma-$ $\mathrm{CD})$ used. We have observed that it was better to use water rather than the water:ethanol solvent system for the inclusion complexation between menthol and $C D$ and 
additionally $\beta$-CD and $\gamma-\mathrm{CD}$ are most favorable choices since they were able to form complexes with menthol in the water solvent system. Despite the high volatility of menthol, our results demonstrated that the stability and temperature release of menthol was sustained to a very high and a broad temperature range $\left(100^{\circ} \mathrm{C}-250^{\circ} \mathrm{C}\right)$ for PEO nanowebs containing $\beta$-CD-menthol-IC and $\gamma$-CDmenthol-IC whereas the PEO nanofibers without $C D$ and without $\mathrm{CD}$ complex could not preserve volatile menthol molecules even during storage. The high temperature release profiles of menthol from PEO/CD-menthol-IC nanowebs strongly suggest that these $\mathrm{CD}$-IC containing nanowebs may have attractive applications for the stabilization and sustained release of volatile additives in general. Here, we have shown that how the durability and temperature stability of menthol can be achieved when incorporated in nanowebs as $\mathrm{CD}$-menthol complex. However, we believe that this is not limited to menthol and/or volatile fragrance/flavor molecules only. The results are very encouraging and open up for a variety of new exciting possibilities for the development of multi-functional nanofibers containing cyclodextrin inclusion complexes. Cyclodextrins can form inclusion complexes with many different molecules (e.g., textile/food/cosmetic additives, drugs, antibacterials, etc) and the incorporation of CD-ICs of these molecules in nanofiber/nanowebs would be particularly attractive for the various applications in textiles, food, cosmetics, bioengineering, packaging, etc.

Acknowledgments: We gratefully acknowledge the funding to the current project NanoNonwovens from The Danish Advanced Technology Foundation, the collaboration with Fibertex A/S, and the Danish Research Agency for the funding to the iNANO center. State Planning Organization of Turkey (DPT) is acknowledged for the support of UNAM-Institute of Materials Science and Nanotechnology through the National Nanotechnology Research Center Project. Dr. Tamer Uyar acknowledges EU FP7-PEOPLE2009-RG Marie Curie International Reintegration Grant (IRG) for funding NANOWEB (PIRG06-GA-2009-256428) project. We also thank to Yusuf Nur for the help in performing the DP-MS experiments.

\section{References and Notes}

1. S. Kaur, M. Kotaki, Z. Ma, R. Gopal, and S. Ramakrishna, Int. J. Nanosci. 5, 1 (2006).

2. J. Bai, Q. Yang, M. Li, S. Wang, C. Zhang, and L. Yiaoxian, Mater. Chem. Phys. 111, 205 (2008).

3. T. Uyar, P. Kingshott, and F. Besenbacher, Angew. Chem. Int. Ed. 47, 9108 (2008).

4. T. Uyar, A. Balan, L. Toppare, and F. Besenbacher, Polymer 50, 475 (2008).

5. T. Uyar and F. Besenbacher, Eur. Polym. J. 45, 1032 (2009).

6. T. Uyar, R. Havelund, Y. Nur, J. Hacaloglu, F. Besenbacher, and P. Kingshott, J. Memb. Sci. 332, 129 (2009)

7. T. Uyar, R. Havelund, J. Hacaloglu, X. Zhou, F. Besenbacher, and P. Kingshott, Nanotechnology 20, 125605 (2009).

8. T. Uyar, J. Hacaloglu, and F. Besenbacher, React. Func. Polym. 69, 145 (2009).

9. T. Uyar, Y. Nur, J. Hacaloglu, and F. Besenbacher, Nanotechnology 20, 125703 (2009).

10. A.-C. Vega-Lugo and L.-T. Lim, Food Res. Inte. 42, 933 (2009).

11. $\mathrm{C}, \mathrm{Xie}, \mathrm{X}$. Li, X. Luo, Y. Yang, W. Cui, J. Zou, and S. Zhou, Inte. J. Pharm. 391, 55 (2010).

12. S. Ramakrishna, An Introduction to Electrospinning and Nanofibers, World Scientific Publishing, Singapore (2005).

13. S. Ramakrishna, K. Fujihara, W.-E. Teo, T. Yong, Z. Ma, and R. Ramaseshan, Mater. Today 9, 40 (2006).

14. A. Greiner and J. H. Wendorff, Angew. Chem. Int. Ed. 46, 5670 (2007).

15. K.-P. Lee, A. I. Gopalan, J. W. Park, D. Ragupathy, and K. M. Manesh, J. Nanosci. Nanotechnol. 9, 115 (2009).

16. J. Szejtli, Chem. Rev. 98, 1743 (1998).

17. E. M. M. Del Valle, Process Biochem. 39, 1033 (2004).

18. A. R. Hedges, Chem. Rev. 98, 2035 (1998).

19. M. V. Rekharsky and Y. Inoue, Chem. Rev. 98, 1875 (1998).

20. K. A. Connors, Chem. Rev. 97, 1325 (1997).

21. W. Saenger, J. Jacob, K. Gessler, T. Steiner, D. Hoffmann, H. Sanbe, K. Koizumi, S. M. Smith, and T. Takaha, Chem. Rev. 98, 1787 (1998).

22. K. Harata, Chem. Rev. 98, 1803 (1998).

23. C. C. Rusa, T. A. Bullions, J. Fox, F. E. Porbeni, X. Wang, and A. E. Tonelli, Langmuir 18, 10016 (2002).

24. T. Uyar, M. A. Hunt, H. S. Gracz, and A. E. Tonelli, Cryst. Growth Des. 6, 1113 (2006).

25. A. Harada, M. Okada, J. Li, and M. Kamachi, Macromolecules 28, 8406 (1995).

26. T. Uyar, A. El-Shafei, X. Wang, J. Hacaloglu, and A. E. Tonelli, J. Incl. Phenom. Macrocycl. Chem. 55, 109 (2006).

27. T. Uyar, C. C. Rusa, A. E. Tonelli, and J. Hacaloglu, J. Polym. Degrad. Stab. 92, 32 (2007).

28. T. Uyar, A. E. Tonelli, and J. Hacaloglu, Polym. Degrad. Stab 91, 2960 (2006).

Received: 24 July 2010. Accepted: 3 October 2010. 